\title{
AN EVALUATION OF THE EFFECTIVENESS OF THE NATIONAL ALLIANCE OF MENTAL ILLNESS'S ENDING THE SILENCE PROGRAM
}

\author{
A Thesis \\ presented to \\ the Faculty of California Polytechnic State University, \\ San Luis Obispo
}

\author{
In Partial Fulfillment \\ of the Requirements for the Degree \\ Master of Science in Psychology
}

by

Sarah L. Taniyama

June 2016 
(C) 2016

Sarah L. Taniyama

\section{ALL RIGHTS RESERVED}


COMMITTEE MEMBERSHIP

TITLE: An Evaluation of the Effectiveness of the National

Alliance of Mental Illness's Ending the Silence

Program

AUTHOR: $\quad$ Sarah L. Taniyama

DATE SUBMITTED: June 2016

COMMITTEE CHAIR: Lisa Sweatt, Ph.D.

Associate Professor of Psychology

COMMITTEE MEMBER: Gary Laver, Ph.D.

Professor of Psychology

COMMITTEE MEMBER: Jennifer Teramoto Pedrotti, Ph.D.

Professor of Psychology 


\begin{abstract}
An Evaluation of the Effectiveness of the National Alliance of Mental Illness's Ending
\end{abstract}

the Silence Program

Sarah L. Taniyama

The National Alliance of Mental Illness's Ending the Silence (ETS) program focuses on the epidemic of mental illness stigma among school-aged youth. The program is targeted specifically at high school-age youth, and aims to educate, dispel myths about mental illness and instill a message of hope and recovery all while encouraging students to reduce the stigma associated with mental illness. A trained presentation team containing two people, one of whom is a young adult living with mental illness or recovered from mental illness, delivers the program. Participants $(n=142)$ completed assessments measuring their thoughts and attitudes towards people with mental illness, as well as a mental health facts questionnaire. Data were gathered from participants before the ETS presentation, after the ETS presentation, and 6 weeks later. The assessments consisted of both qualitative and quantitative data. Content analysis of the qualitative data revealed a consistent improvement in participants' understanding and definition of mental illness. Youth reported understanding that mental illness can be a biological as well as developed illness. The majority of students (61.3\%) self-reported their attitudes towards people with mental illness had become more positive after the presentation. The results of this study indicate that the Ending the Silence program is meeting its identified goals and objectives. 


\section{ACKNOWLEDGMENTS}

I would first like to thank my thesis chair. Dr. Lisa Sweatt for your support during the entire process. Your encouragement, patience, and guidance never wavered, and you kept me sane throughout the process. You are someone I will continue to admire the rest of my professional and academic career, and you have set a wonderful example for me to model myself after.

I would also like to thank my other committee chair members, Dr. Teramoto Pedrotti and Dr. Laver for their willingness to support me during this process. Both of you are inspiring and busy and yet took the time to provide me guidance throughout the writing process. A special thank you to Dr. Laver as well for sitting in on my committee last minute and for all of your guidance through the analysis of my data.

Thank you to Joe Johnson, for allowing me to evaluate the amazing work you and your team are doing with the ETS program, and thank you to the schools that allowed me to run assessments during your class time and welcomed me in so warmly.

To my friends and family, thank you for being understanding of this long tedious process, and supporting me the entire time. Thank you for checking in on me and seeming interested in what I had to tell you about my research even if you didn't want to!

To my coworkers at CALM, thank you for always supporting me, praising me for my commitment and being a sounding board for me when I needed to process.

Lastly, my fiancé, who has been so patient, kind, and encouraging throughout everything, and even if you had no idea what I was talking about you seemed intrigued and interested and made me always feel heard. 


\section{TABLE OF CONTENTS}

LIST OF TABLES

\section{CHAPTER}

1. INTRODUCTION

2. LITERATURE REVIEW 4

2.1 Introduction 4

2.2 History of Stigma $\quad 4$

2.3 Mental Health Stigma $\quad 6$

2.4 Effects of Stigma $\quad 7$

2.5 Stigma Prevention Programs $\quad 8$

2.6 Youth Mental Health Statistics $\quad 10$

2.7 Effects of Stigma on Youth 11

2.7.1 Influence of Family 11

2.7.2 Influence of Peers 13

$\begin{array}{ll}\text { 2.7.3 Influence of Media } & 14\end{array}$

2.7.4 Influence of School 16

2.8 Mental Health Stigma Programs for Youth 17

2.9 The Risk of Mental Health Stigma in School 20

2.10 Summary $\quad 21$ 
2.11 Ending the Silence Program

$\begin{array}{ll}\text { 5. DISCUSSION } & 35\end{array}$

$\begin{array}{ll}5.1 \text { Limitations } & 38\end{array}$

5.2 Implications for Stigma Reduction Programs Aimed at Youth 39

5.3 Implications for Future Research $\quad 40$

$\begin{array}{ll}5.4 \text { Conclusion } & 40\end{array}$

$\begin{array}{ll}\text { REFERENCES } & 42\end{array}$

APPENDICES

A. ETS 10 Key Messages $\quad 47$

B. Health Education Content Standards $\quad 48$

$\begin{array}{ll}\text { C. Letters of Support } & 50\end{array}$

D. Parental Permission Form $\quad 54$

E. Youth Assent Form

F. Revised Attribution Questionnaire $\quad 57$ 
G. Mental Health Facts $\quad 58$

H. Personal Beliefs Survey $\quad 59$

$\begin{array}{ll}\text { I. Presentation Evaluation } & 60\end{array}$

J. Demographic Questionnaire 61 


\section{LIST OF TABLES}

Table

Page

1. Listwise Descriptives of the Attribution Questionnaire

2. Listwise Descriptives of the Myths and Facts Measure

3. Listwise Descriptives of the Personal Beliefs Measure

4. Group Statistics 


\section{CHAPTER 1}

\section{INTRODUCTION}

The world of a child consists of home, school, and peer relationships; those are the three most important influences on youth today. Mental illness in children can affect all three of those worlds. When early diagnosis or early interventions are missed, a child may have difficulties at home, completing work at school, or forming friendships with like-aged peers, but it can also interfere with their ability to hit developmental milestones, build healthy attachments through adolescents, and it may continue to create problems into their adulthood (Centers for Disease Control and Prevention, 2013). According to National Alliance on Mental Illness (NAMI, 2010), approximately four million children and adolescents in the United States suffer from a serious mental disorder, causing significant functional impairments across settings. In any given year, only 20 percent of children with mental disorders are properly identified, diagnosed and receive mental health services (NAMI, 2010).

The Substance Abuse and Mental Health Services Administration (2007) defines mental illness as:

a common health condition that causes changes in a person's thinking, mood, and behavior. Mental health and mental illness can be pictured as two points on a continuum with a range of conditions in between. When these conditions are more serious, they are referred to as mental illnesses and include depression, schizophrenia, anxiety and others, which may require treatment and support. Mental illness can happen to anybody regardless of age, culture, race, gender, ethnicity, economic status, or location. (SAMHSA, 2007, p. 2).

In regards to how stigma is defined, Erving Goffman (1963) defined stigma as a social construct, where people can change from a "normal" to "discredited" social status. Corrigan and Watson (2002) explained that mental health stigma are public negative 
beliefs about people with mental illness and has three sub-categories: stereotype, prejudice, and discrimination.

There are many ways in which mental illness stigma can exacerbate the negative impact of being a child trying to cope with mental illness. It can create and facilitate fear, anger, barriers, and misunderstandings for both the stigmatized and the stigmatizing groups. However, most research conducted on the public stigma of mental illness has been with adult populations. A study conducted by Vogel, Bitman, Hammer, and Wade (2013), looked at public and self-stigma over time using college age participants. This study found that public stigma internalized as self-stigma over time. Rüsch, Angermeyer, and Corrigan (2005) found many anti-stigma programs all over the world that target their interventions at adults. For example, Stigmabusters is a NAMI program that protests against negative media representations of mental illness in the United States. Bavarian Anti-Stigma Action, based in Munich, and the Like Minds Like Mine campaign in New Zealand includes local, regional, and national initiatives. There are many other programs similar to these throughout the world; however, these projects and programs only target adults in their efforts to decrease stigmatizing attitudes and beliefs.

There is a growing need for mental health education and mental illness antistigma interventions aimed at today's youth. There are disheartening statistics about youth suffering from mental illness that show the adolescent population could benefit from an increase in awareness, education, and acceptance of mental illness. According to NAMI's Child and Adolescent Action Center (2010), over 90\% of children and adolescents who commit suicide have a mental disorder. Furthermore, approximately $50 \%$ of students ages 14 and older living with mental illness drop out of high school, 
which is the highest dropout rate for any disability group (Adolescent Action Center, 2010).

Despite the need, there is a paucity of mental health education and mental illness anti-stigma programs aimed at youth compared to those targeting adults. Furthermore, there is insufficient research on the effectiveness of the youth-based anti-stigma programs currently in place. The National Alliance of Mental Illness's (NAMI) Ending the Silence (ETS) program focuses on reducing the stigma of mental illness among school-aged youth. ETS is a 50-minute presentation given in freshman and sophomore high school classes. The program aims to educate and dispel myths about mental illness, reduce the stigma associated with mental illness, and instill a message of hope and recovery. NAMI's ETS program is utilized nationally; however, little research has been conducted to date demonstrating its effectiveness. The purpose of this study was to evaluate the effectiveness of ETS at meeting its stated goals. 


\section{CHAPTER 2}

\section{LITERATURE REVIEW}

\subsection{Introduction}

This study is important as it speaks to the need for more mental health education for youth due to the effectiveness of the Ending the Silence Program. This study's purpose was to evaluate the effectiveness of the NAMI ETS program at meeting its stated objectives. Students were given a pre-test assessment before exposure to ETS, a post-test packet immediately following the program, and a 6-week follow up to assess sustainability of ETS's objective and goals. This literature review examines the empirical evidence related to stigma, adolescent mental illness and youth anti-stigma programs. The history of stigma is followed by an introduction to mental health stigma and its effects, and then discusses existing stigma prevention programs; both adult and youthbased programs. Lastly, the NAMI ETS program is also discussed.

\subsection{History of Stigma}

The definition of and society's reaction to stigma has evolved over time. In an article by Kleinman and Hall-Clifford (2009), the authors explain that the modern definition of stigma is credited to Erving Goffman (1963), who viewed stigma as an idea based on social construction. Goffman (1963) defined stigma as "an attribute that is deeply discrediting" and that stigma reduces a person "from a whole and usual person to a tainted, discounted one" (Goffman, 1963, p.3). Researchers Link, Struening, NeeseTodd, Asmussen, \& Phelan (2001) studied stigma and included the concepts of structural and institutional stigmatization, and more recently, anthropologists have contributed to 
the conversation by adding that stigma is in fact embedded in the moral experience, and stems from the ideas of morality and ability to meet social obligations. Major and O'Brien (2005) stated that many social psychological definitions of stigma agree that stigma consists of an attribute or characteristic that makes people appear different leading to a devaluation in society, and stigma is dependent on relationship and context

The study of stigma began in the early 1900s (Scheyett, 2005). Stigma may manifest both on a public level and a personal level. Many authors have noted the differences between concepts such as public stigma versus self-stigma. Public stigma refers to the perceptions endorsed by the general population, promoting stigmatizing beliefs and attitudes (Vogel, Wade, \& Haake, 2006). Self-stigma is the idea of a person having negative beliefs about themselves, which may result in low self-esteem or low self-efficacy (Corrigan \& Watson, 2002). It has been seen that self-stigma is ultimately internalized public stigma; the stigmatizing attitudes of others can quickly turn inward against the member of the stigmatized group (Vogel, Bitman, Hammer, \& Wade, 2013).

The treatment of the mentally ill has been controversial for centuries in America. From the influences of Philippe Pinel and Dorothea Dix, there have been many advocates for those with mental illness. Philippe Pinel was said to have been the first to "remove the chains from the mentally ill” (Levine, 2015, p. 1130). Dorothea Dix was a pioneer for people with mental illness as well; she worked to help challenge the belief that people with mental illness could not be helped (Parry, 2006). Gostin (2008) discusses the abusive and punitive history of the treatment of the mentally ill. The author mentions that civil rights activists in the 1960 s fought to close the mental institutions and give the mentally ill the rights they deserve. These activists were continuing with the mission that 
Pinel and Dix started in the 1800s. Unfortunately, their efforts were not met with great success, as the promised community mental health services were underfunded and the public was banning together to get the mentally ill out of their neighborhoods (Gostin, 2008). Gostin (2008) explains that the old mental institutions may have been closed but jails, prisons, and homeless shelters replaced them.

There seem to be few things stigmatized as publicly as mental illness. When someone has a physical illness they are not considered undesirable, or deeply discredited by society. In fact, when someone is physically sick they have cancer, yet when someone is mentally ill they are schizophrenic (Rüsch, Angermeyer, \& Corrigan, 2005). Kleinman and Hall-Clifford (2009) discussed the continued transformation of stigma, and asserted that there is a current trend in the de-stigmatization of mental illnesses. It is apparent that the battle to end mental illness' stigma has only just begun, and society seems to have varying reactions to illnesses of the mind.

\subsection{Mental Health Stigma}

In a study done by Wahl (1999) 1,301 people with severe mental illness (SMI) reported that their experiences with stigma are at the root of their feelings of discouragement, hurt, anger, and low self-esteem. Three types of stereotypical beliefs towards mental illness have been frequently cited in the research: authoritarianism, fear and exclusion, and benevolence (Corrigan, Edwards, Green, Diwan, \& Penn, 2001; Couture \& Penn, 2003; Brockington, Hall, \& Levings, 1993). Authoritarianism is the belief that people with SMI are irresponsible and are not capable of taking care of themselves; fear and exclusion is the belief that people with SMI should be feared, are dangerous, and should be isolated from communities; lastly, benevolence is the belief that 
people with SMI are innocent and naïve, and are in need of others in order to survive (Couture \& Penn, 2003). People with mental illness face difficulties on many different levels, they are dealing with the symptomology of their illness, facing scrutiny and judgment from a society who ultimately misunderstands them, and are attempting to stay active in seeking treatment and participating in activities to decrease symptomology all while battling against stigma.

\subsection{Effects of Stigma}

Once stigma has become internalized, it has many adverse affects. People who experience the effects of stigma may face many barriers. For instance, it may impede their ability and willingness to seek treatment, they may avoid treatment altogether for fear of scrutiny from others, or they may be labeled in an undesirable way (e.g., weak, crazy, unstable, etc.). Research has shown that people who experience self-stigma are more likely to have lower self-esteem (Link et al., 2001). Stigma may create a barrier in their personal or professional lives as well. Stigma may interfere with a person's ability to form a positive and healthy attitude about him or herself and their ability to perform tasks, and overall capabilities (Vogel et al., 2013). According to the Center's for Disease Control and Prevention (2011), stigma may cause people to refrain from daily activities, causing them to isolate, which may result in an inability to form healthy relationships and attachments to others.

Stigma can also have effects on individuals on an institutional level. Stigma can exclude people from accessing housing, employment, insurance, and appropriate medical care (Center's for Disease Control and Prevention, 2011). According to Corrigan, Kerr, and Knudsen (2005), institutional discrimination manifests itself as rules, policies, and 
procedures of private and public entities in positions of power that intentionally restrict the rights and opportunities of a group of people. This process is unfortunately familiar in this country, restricting the rights of specific groups of people based on attributes that are uncontrollable to them.

The Americans with Disabilities Act was signed into law in 1990 (United States Department of Justice Civil Rights Division, n.d.) in order to ensure the rights of peoples with disabilities. Laws such as the Americans with Disabilities Act, Fair Housing Act, Air Carrier Access Act, National Voter Act, Civil Rights of Institutionalized Persons Act, and Individuals with Disabilities Education Act (United States Department of Justice: Civil Rights Division, 2009) are in place to help decrease the institutional discrimination and stigma people with physical and mental disabilities may face. With mental illness it can be a far more intrusive battle to fight for your rights, as it is often an illness that is not visible from the exterior. There is a process of having to prove your disability status someone with a physical disability may not experience. People who are in positions of power (e.g., landlords, lawmakers, employers) are in need of improved understanding and education about mental illness. Corrigan et al. (2005) suggest that anti-stigma programs are more successful when they target specific groups of people rather than just the general public, and that changing beliefs and attitudes towards mental illness is likely to be more successful when power groups are targeted in the settings in which they are likely to discriminate

\subsection{Stigma Prevention Programs}

There are several active programs to reduce the stigma of mental illness both in the United States as well as in other countries. The Substance Abuse and Mental Health 
Service Administration (SAMHSA) has invested millions of dollars in anti-stigma programs, including public service announcement campaigns that reach the general public (Corrigan \& Shapiro, 2010). A review of the literature revealed that many countries are involved in the initiative to reduce stigma, and there are many existing stigma preventions programs in countries such as Germany, New Zealand, Canada, Australia, Korea, Israel, France, and many others (Rüsch et al., 2005; Lindsay \& Edwards, 2013).

Three main strategies have been utilized to fight stigma: protest, education, and contact (Rüsch et al., 2005). Protest strategies draw attention to the injustices of various forms of stigma, and then penalize the offenders (Corrigan \& Shapiro, 2010). Educational strategies provide factual information, in hopes of replacing inaccurate stereotypes (Corrigan \& Shapiro, 2010; Couture \& Penn, 2003). The third strategy, interpersonal contact, attempts to dissipate negative beliefs by placing people in direct contact with someone from the stigmatized group (Couture \& Penn, 2003). Organizations like NAMI have utilized protest strategies in order to dispel inaccurate depictions of mental illness from being displayed on television (Corrigan \& Shapiro, 2010). Most anti-stigma programs utilize education or contact; however, it has been found that the most effective and promising strategy is combining educational strategies with contact (Couture \& Penn, 2003). In a study conducted by Koller and Stuart (2011), participants were surveyed about an anti-stigma symposium they had seen and asked to report what they liked best about the symposium. The majority of respondents reported enjoying the personal stories and first-hand narratives from the people with mental illness about their life and daily experiences. The results of the study conducted by Koller and Stuart (2001) showed that 
the symposium improved students' responses. Before the symposium $14 \%$ of students fell into the category of non-stigmatizing responses, and after the symposium, $46 \%$ of students fell into that category. An important thing to remember about anti-stigma programs and prevention is that they aim to do more than educate, expose people to the stigmatized group, and expose the injustices of society. They also aim to find ways to apply the knowledge or new understanding and create behavioral changes. Couture and Penn (2003) explained that reducing stigma benefits both the in-group and the out-group, in that it has the potential to eradicate the fears of the general public, as well as improve the lives of those living with mental illness.

\subsection{Youth Mental Health Statistics}

Adolescence can be a time of increased stress, social pressure, and accelerated development, which may lead to emotional regulation disturbance or other behavioral problems (Lindsey \& Kalafat, 1998). The statistics on mental illness during adolescence depicts the need for attention on this particular age group and developmental stage. According to NAMI (2013), 50\% of all chronic mental illness begins by age 14. Many adults living with mental illness may have shown symptoms as an adolescent. Without proper treatment and care during adolescence the mental illness can hinder a person from a healthy development into their adulthood. There are many who are aware of the increase in suicide among youth due to the media's exposure of these stories. NAMI (2013) reports that suicide is not only more common than homicide in the United States, but it is the third leading cause of death for ages $15-24$, and $90 \%$ of those who die by suicide had one or more mental illnesses. 
There is beginning to be an increase in awareness of adolescent mental health issues due to the statistics like the ones found through NAMI. There are many early warning signs of mental illness in adolescence that are discredited or misinterpreted to be a symptom of their age. Almost $50 \%$ of youth ages $8-15$ years old with a mental illness never receive mental health services (NAMI, 2013). Studies have repeatedly shown that stigma and the fear of what peers or other people may think is a strong deterrent from youth disclosing about their illness or reaching out for help (Moses, 2010). In a research study conducted by Moses (2010) the study found that $32 \%$ of the adolescent sample reported they frequently or very often felt people might not like them if they knew they had a behavioral or emotional issue. During this stage of life, attitudes and beliefs are being shaped, personalities are being formed, and with that comes the fear of being disliked. Stigma can be detrimental to youth with mental illness as they are already striving to fit in socially and develop their identity and independence or autonomy (Moses, 2010).

\subsection{Effects of Stigma on Youth}

\subsubsection{Influence of Family}

During adolescence, youth are very susceptible to the thoughts and opinions of others. Most assume that like-aged peers mostly influence adolescents, but as research has demonstrated the opinions of their parents are just as influential as that of their peers, particularly the parents of youth with mental illness (Moses, 2010). Moses (2010) conducted a study addressing the questions of adolescents' and parents' perceptions of stigma. Moses (2010) asked questions regarding perceptions of the cause, controllability, and anticipated outcome of the adolescent's mental illness, as well as the question of 
what extent do illness perceptions of the adolescent and their parent relate to the adolescent's self-stigmatization. Moses (2010) found that when the parents of a child with mental illness feels stigmatized by others, it is more likely to cause the adolescent to self-stigmatize. Goffman (1963) coined the term courtesy stigma, referring to the discrimination, rejection, or avoidance by others who blame parents for causing the problems, and the parents in turn experiencing a sense of shame and embarrassment. Parents are very influential in an adolescent's life, and an adolescent who has disclosed their mental illness to their parents are in need of support and acceptance. However, the parents of these youth are not exempt from the shame and stigma attached to mental illness. Some parents may go as far as having an inclination to conceal their child's problems from others (Moses, 2010).

There are many studies and stories depicting the discrimination of adults towards other adults with mental illness, or youth towards other youth, but rarely research depicting the discrimination of stigmatizing attitudes of adults towards youth with mental illness. Martin, Pedcosolido, Olafsdottir, \& Mcleod, (2007) discovered that some adults are reluctant to interact or have their children interact with children who have mental illness. The attitudes of others can be very detrimental to a person's self-esteem, particularly someone like an adolescent who is developing their sense of self and searching for their individual identity. The results of these studies were not all negative and disadvantageous to the youth and their families. Moses (2010) did find that adolescents reported less self-stigma when their parents reported more optimism about their child's future and disclosed a greater sense of faith in their child. Familial support 
is important for recovery and for decreasing self-stigmatization in the adolescent and the parents of the child.

\subsubsection{Influence of Peers}

According to Susman et al. (1993), youth are beginning to want to turn to their peers for advice, separate themselves from their parents and the ideas and values imparted on them during their childhood, and begin to develop their own values and beliefs (as cited in Chandra and Minkovitz, 2007, p.765). There are certain feelings and experiences everyone will most likely experience in their adolescent years: things like embarrassment, rejection, self-consciousness, and maybe even loneliness. Many of these feelings can be decreased with a good support system. Moses (2010) found that many adolescents living with mental illness reported having trouble making or keeping friends, and that is part of what perpetuates their mental health problems. They also reported more embarrassment, self-consciousness, and fear of rejections on account of their mental health problems.

Many youth are more likely to turn to their friends in a time of need rather than to their parents. Adolescence is a time to form connections, and part of those connections is sharing important milestones and moments in your life. Adolescence is a time where the child begins to attempt to obtain more responsibility for themselves, and their actions in order to appear separate from their parents. Chandra and Minkovitz (2007) explained that, in research, early adolescence has received significantly less attention in regards to help-seeking and mental illness, even with the understanding that it is such a critical time of life during which young people are beginning to take more initiative in help-seeking.

In their research, Chandra and Minkovitz (2007) surveyed $8^{\text {th }}$ grade students using the 
Teens Addressing Mental Health Services study to explore the relationship between teens' attitudes towards mental health services as well as their willingness to use mental health services. In regards to supporting their peers who live with mental illness, several of the students identified that they do know someone living with mental illness, but explained that talking about mental illness with their peers brings a "certain awkwardness" (p. 770).

In regards to the perceived social consequences of utilizing mental health services, Chandra and Minkovitz (2007) discovered many of the teens felt that while some of their classmates would be accepting, most would react negatively if they found out someone they knew was seeking mental health services. The teens in this study also revealed they felt that peers would start avoiding a friend who needed help, mostly based on the fact that they find the topic uncomfortable. There is a certain level of secrecy and discomfort associated with youth mental illness, and when there is very little transparency and false depictions of mental illness in the media, there is likely to be misunderstandings, avoidance, and stigma involved with youth mental illness.

\subsubsection{Influence of Media}

While generations before had to read news the next day in the newspaper, or wait for a breaking news story on the nightly news, teens today have everything they need in the palm of their hands. Characters with mental health problem have often been portrayed as violent, unpredictable, and unable to recover. The media uses false explanations for a character's mental illness. It is not just the depiction of people living with mental illness in the media that can be controversial but even headlines in news articles can be a misrepresentation.. Mullins (2012) noted that newspaper headlines might evoke feelings 
of fear or repulsion among readers towards people who have mental illness. In the research covering mental illness and the mass media, there is a common theme among researchers that both characters with mental illness, and stories covering mental illness link mental illness with criminality, violence, and danger (Mullins, 2012). Morgan and Jorm (2009) found that with the mass media being such an important source of information about mental illness, there is a concern because negative media reporting has been implicated in the formation of negative attitudes towards people living with mental illness.

It is likely that children and adolescents are receiving a majority of their information from the mass media. Wahl, Hanrahan, Karl, Lasher, and Swaye (2007) spoke to the idea that children and adolescents' opportunities to learn about mental illness from other sources (i.e., higher education, job experiences, etc.) are limited, and with that limited access to other sources of information they are likely to be even more reliant than adults on mass media, and more importantly, more susceptible to the influence of mass media. In studies regarding adolescents' exposure and use of media, Morgan and Jorm (2009) looked at adolescents' ability to recall news stories about mental illness. According to their findings, adolescents were more likely to describe mentally ill people as dangerous and violent after reading news reports of mentally ill individuals committing crimes, compared to a control group who was given factual articles about mental illness. Many of the adolescents in the study reported having difficulty recalling any stories about successful recovery from mental illness, which is consistent with the lack of reporting on that particular type of story. It is not just adolescents who are dependent and consumed by mass media; it begins with young children. Wahl et al. 
(2007) looked at children's television shows, and found that many of the characters who appeared to have mental illness were referred to using slang terms like "nuts" "bananas" "twisted" "deranged" "wacko" and "loony". These characters also had a distinct unattractiveness to them, often with characteristics such as rotting teeth, unruly hair, heavy eyebrows, narrowed eyes, and bad breath. The other characters in the television shows tended to treat the character with mental illness badly, make fun of them, and exclude them. What was discussed in this research is that the depiction of mentally ill characters in children's programing is creating a problematic model of how to behave towards those with mental illness, and in providing these children with opportunities to obtain vocabulary and slang that is hurtful and disrespectful to those with mental illness. The mass media has an obligation to educate themselves and others on the true meaning of mental illness and to depict characters that can accurately represent the issue that so clearly needs more accurate attention.

\subsubsection{Influence of School}

The main focus of the research regarding mental health stigma is the importance

of education. Education is a crucial and vital part of decreasing stigmatizing attitudes and beliefs. Youth spend much of their daily lives at school from the time they are 5 until they are 18 years old. With the understanding that youth are spending most of their time at school, it would seem appropriate to make school a safe and comfortable place for all students, but especially for those who may be struggling to discover themselves, whether it be because of mental illness, gender identity confusion, sexual confusion, or home conflicts. It is important for school to be a place where students feel heard, understood, and most importantly, safe. 
Chandra and Minkovitz (2007) found that many adolescents disclosed not understanding the difference between mental illness and mental retardation, assuming that classmates with mental health issues were in special education classes. Findings such as these are evidence of the lack of education and understanding of mental illness. There are many influential people in a young person's life: peers, parents, but also teachers. Teachers and school staff may spend more time with the adolescents than some of their own parents. Adolescents spend 45 hours a week on average at school with their teachers and other school administration. Many of the educators may be the only positive adults in the student's life. In their findings, Chandra and Minkovitz (2007) found that many students sensed that their teachers were reluctant or uncomfortable dealing with adolescent mental health issues. Students voiced that they wanted teachers to recognize that their mental illness affected how they attended to classroom activities, but some students felt that there were some teachers who did not express any concern. There is a need for education across all ages concerning mental illness and its effects on a person in the different facets of their lives. It may be beneficial for teachers to be trained on how to identify signs of mental illness and understand that it may affect a student's ability to learn at times. Overall, schools, parents, peers, and other adults would benefit greatly for educating themselves on mental illness, but especially on what it is like to live with mental illness as a young person, and how it may feel to be ostracized for something you yourself may not even fully understand.

\subsection{Mental Health Stigma Programs for Youth}

The twenty-first century has seen a rise in anti-stigma programs for youth. Mental illness is becoming a more prevalent topic among youth today. Stigma researchers are 
aware that in order to elicit change, the education needs to happen where the stigmatizing beliefs, behaviors, or attitudes are most likely occurring. For youth, that environment is school. Many programs have utilized different mediums for delivering education about mental illness. Stuart (2006) found video-based education to be an effective way to increase students' knowledge and decrease social distancing behaviors. Spangnolo, Murphy, and Librera (2008) found that social contact and presentation of accurate information was successful in students reporting less stigmatizing attitudes.

Some research has taken a creative approach to education. Essler, Arthur, and Stickley (2006) assessed the effectiveness of a school-based intervention in which a professional theater company that had experience working with the school-age population and subject matter performed for students in order to provide education on mental illness. During the first phase the group facilitated a quiz, drama, and games focused on mental illness. The second phase was aimed at building self-esteem and awareness of the student's attitudes towards people with mental health problems. The researchers conducted a pre- and post-evaluation as well as a one-month follow up. Students showed improvement in knowledge of mental illness following the intervention. However, the scores decreased from baseline (pre-test) to follow-up.

In a review of several educational interventions aimed at changing students' attitudes towards mental illness Sakellari, Leino-Kilpi, Kalokerinou-Anagnostopoulou (2011) reviewed 13 studies of educational interventions aimed at changing students' attitudes towards mental illness. Of these 13 studies, two were from the United States. Similarly, Lindsay and Edwards (2013) conducted a systematic review of disability awareness programs for children. Although not specific to mental illness, some of the 
programs did cover mental illness under the umbrella of disability. Out of the 42 programs reviewed in this article, 13 studies were from the United States. Although it is promising that the number of programs and research studies evaluating the programs continues to grow, there is a disparity between other countries' initiative to raise awareness and educate youth regarding mental illness and the United States. In England, Pinfold, et al., (2003) conducted a study in which they aimed to measure the effectiveness of a program aimed at increasing mental health literacy and challenging negative stereotypes of mental illness. They used a pilot measure that consisted of factual statements, attitudes statements, and social distance questions. Small but significant changes in student's mental health literacy were found in this study, and it was said that education workshops may have a small statistical impact, but they have a positive impact on students' views of mental illness and those living with mental illness.

In the study conducted by Chandra and Minkovitiz (2007), some participants were able to share that their views changed after they had gained more knowledge and understanding of mental health, and family conversations about mental health had an impact on the teens' comfort to discuss mental health issues and concerns. In one study, of a mental health education program, Pinfold et al. (2003) found that $73 \%$ of the students self-rated their attitudes as more positive towards people with mental illness immediately after the workshop, and at the 6 month follow up, $61 \%$ of those students retained their positive attitude. Thus, in the few studies conducted to date, it does appear that educating youth on the facts of mental illness and the effects of stigma has beneficial outcomes. 


\subsection{The Risk of Mental Health Stigma in School}

The importance of the topic of mental health stigma is growing in popularity as well. Unfortunately, more and more students who are inflicting harm on themselves or others are being revealed as people who are living with mental illness. An adolescent spends a great deal of their time at school. When a student is uncomfortable or feels ostracized in the place they spend a majority of their time, it creates an unsafe space or a place they would like to avoid. The Center for Disease Control and Prevention has been collecting data on school-associated deaths since 1992. In 2014, the Injury Prevention and Control Division of Violence Prevention, reported that between 14 and 34 students are victims of homicide on school campuses, and nearly 50 percent of homicide perpetrators gave some type of warning signal. Karch, Logan, McDaniel, Floyd, and Vagi (2013) examined the circumstances that precipitated suicides among 1,046 youth ages 1017 from 2005-2008 and found that suicide is more common among youth who have mental health problems, low self-esteem, peer and parental relationship problems, partner problems, or academic problems. Their findings also reflected that problems at school played a significant role in youth suicide, and that among the students with school problems who ended their lives, $25 \%$ of them were recently bullied.

Spagnolo et al., (2008) explained that stigma negatively affects feelings of social connectedness and can work against people's efforts in recovery. Social connectedness is important at any stage of life, but particularly among adolescents. Creating relationships is an important part of growth and exploration of one's identity. Many researchers have claimed that mental health stigma could prevent adolescents from seeking treatment. Bulanda, Bruhn, Byro-Johnson, and Zentmyer (2014) also suggest that mental health 
stigma could leave youth feeling isolated and rejected. It can effect an individual's selfesteem, ultimately effecting the way the adolescent sees himself or herself. Adolescents may begin to internalize messages they hear from peers who do not understand or believe the stereotypes of mental illness. Mental health stigma can result in individuals feeling isolated, experiencing bullying and rejection, and may ultimately lead to feelings of desperation that often precipitate acts of school violence or suicide (Bulanda et al., 2014). There are other risk factors when a child or adolescent struggles to feel understood or accepted at school but a student ending their lives or the lives of others may be the worst result of mental health stigma.

\subsection{Summary}

Research to date has demonstrated there is a benefit to educating youth about mental illness. Children as young as three years old are beginning to create worldviews, and understand the differences between negative and positive beliefs. (Bulanda, et al., 2014 p. 79). Sakellari et al., (2011) state that adolescence is the opportune time to encourage positive attitudes; it is a time of rapid advance in cognitive abilities and intense acquisition of new information. If there is a focus on reducing negative beliefs and stigmatizing attitudes during this time, it will most likely lead to a productive adult life and decrease chances of continuing the cycle of stereotypes and false information regarding mental illness.

Mental health promotion in schools contributes to making the overall environment at school healthier and more productive (Essler et al., 2006). Healthier schools would ultimately lead to safer schools, leaving room for more focus on education and creating successful adults. Han and Weiss (2005) bring attention to the difficulty of implementing 
school-based mental health programs and discuss the importance of having a knowledgeable and supportive school leadership team. Having such administration and staff behind the mission can be instrumental in making mental health education a priority in schools. The importance of educating youth about the dangers of stigma, as well as the truth behind mental illness is ultimately to cease the cycle of social injustice toward people with mental illness.

\subsection{Ending the Silence Program}

The Ending the Silence Program created by the National Alliance of Mental Illness (NAMI) began in 2006 in DuPage, Illinois. Ending the Silence (ETS) is a 50minute presentation given in freshman and sophomore health, science, or psychology classes. A trained presentation team containing two people, one of whom is a young adult who is living with mental illness or recovered from mental illness, delivers the program. The presentation includes personal anecdotes, educational slides, videos, and discussion. This program is offered to schools at no cost, provides students the opportunity to learn from a "real life" young person with mental illness, and gives them the chance to ask questions. It helps normalize mental illness for students who are living with mental illness and helps them to realize they are not alone. This program helps to dispel myths about mental illness and instill a message of hope and recovery all while encouraging students to reduce the stigma associated with mental illness. Some of the key messages of the ETS program are: mental illness is just that, an illness, like any other physical illness; mental illness is not anyone's fault or something to be ashamed of; there are early warning signs of mental illness; you are not alone and there are many resources you can look to for support; and recovery is possible (NAMI, 2015, See Appendix A). The ETS 
program is a natural part of the academic curriculum for California Schools. The program covers 13 of the Health and Education content standards for high school students (California Department of Education, 2012, See Appendix B). According to statistics gathered from researchers at NAMI, as of 2012 there have been over 1,000 ETS presentations reaching approximately 35,000 students nationwide. In California, there have been approximately 750 ETS presentations reaching 23,818 students.

There is a need for programs like ETS in schools. In a survey by the Annenberg Public Policy Center (as cited in the Ending the Silence Outreach Strategies Guide, NAMI, 2014, p. 108) only $34 \%$ of school administrators contacted in the survey reported that their school had a clearly developed and defined process for identifying students with mental health concerns. Schools are required by law to have a referral process in place (NAMI, 2014). An argument from the outreach and marketing of ETS is that many schools concerned with students' mental health are lacking resources. There is often only one person on staff who carries the weight of the whole student body's mental well being on their shoulders, and these professionals often only work part time (NAMI,2014, p.108).

The NAMI chapter in San Luis Obispo County has conducted 78 presentations, reaching approximately 3,003 students from 2012-2014. According to the San Luis Obispo County program coordinator, the evaluation of the ETS program has not been implemented for a couple of years. Currently there is no evaluation of the presentation to measure its effectiveness. The NAMI ETS program is a national program that reaches thousands of young people every year. It is essential that a prevention/early intervention program, such as ETS, which reaches so many youth and has such a critical mission, be 
evaluated for its effectiveness in meeting its stated goals and objectives. Therefore, the purpose of this study was to evaluate the effectiveness of the ETS Program in reducing stigma about mental illness, increasing factual knowledge about mental illness, and increasing positive beliefs about people with mental illness. The following hypotheses were examined:

\subsection{Hypothesis}

H1: The Ending the Silence program will decrease stigmatizing attitudes as measured by the Attribution Questionnaire (r-AQ)- Short form for Children.

H2: The Ending the Silence program will improve the factual knowledge and understanding of mental illness as measured by the Myths and Facts Measure.

H3: The Ending the Silence program will improve positive personal beliefs about people with mental illness as measured by the Personal Beliefs scale.

H4: The positive changes in stigmatizing attitudes and knowledge and understanding of mental illness will be sustained in a 6-week follow up assessment.

H5: Students who know someone with mental illness or have a mental illness themselves will report less stigma about mental illness, will have greater knowledge about mental illness, and will report fewer negative personal beliefs about mental illness as compared to students who do not have a personal experience with mental illness. 


\section{CHAPTER 3}

\section{METHODS}

\subsection{Participants}

The director of the ETS program identified participating schools. Three high schools participated in the study. Student participants were local high school students enrolled in health, science, or psychology courses at their school. Classrooms were picked based on the interest of the teacher and the commitment to participate in the program from administration and faculty (See Appendix C). There were 142 participants $(n=142)$ ranging in age from $14-18$ years old. The mean age for participants was 15.02 . Of the participants used $47.2 \%(n=67)$ identified as male and $52.1 \%(n=74)$ identified as female. Students were asked to self-report ethnic identity and 69.7\% $(n=99)$ of students identified as White/Caucasian and 28.2\% $(n=40)$ identified as non-white. At the pre-test students were asked if they knew someone with a mental illness or had mental illness themselves and $81 \%(n=115)$ of students reported knowing someone who has a mental illness and $17.6 \%(n=25)$ reported not knowing anyone who has mental illness during the pre-test demographic questionnaire. Some student chose to omit questions and demographic information, which lead to the missing data. Students were given a parental consent form to take home to parents to sign (See Appendix D).

\subsection{Materials}

The Revised Attribution Questionnaire (R-AQ) - Short Form for Children (Watson et al., 2004): This was used to measure participant's reaction to a short vignette about a new student joining the class who comes from a special school and who has a mental illness. 
The measure was developed from the original Attribution Questionnaire -27 (Corrigan, Markowtiz, Watson, Rowan, \& Kubiak 2003; Corrigan \& Watson, 2002). This measure evaluates nine constructs: responsibility, anger, pity fear, dangerousness, help, coercion, segregation, and avoidance. Previous research has found the internal reliability of the Attribution Questionnaire-27 to be high $(\alpha=.70)$, with each construct measured separately (Corrigan et al., 2003). Based on the psychometric evaluation of the r-AQ it has been said to be a reliable and valid measure of youth's emotional reaction to people with mental illness. Cronbach's alpha for the r-AQ for this study was .67 with all eight items. This measure was adapted for the purpose of this study.

The Global Anti-Stigma Program Measurement Toolkit Myths and Facts Measure (World Psychiatric Association, n.d): This measure was derived from a Canadian pilot project and was revised to fit the objectives of the study. Language was changed to reflect a more broad measure of mental illness rather than specifically schizophrenia, which was what the original measure used. This measure included five knowledge statements to help debunk myths about mental illness. There is no cited reliability or validity for the original Myths and Facts measure, although in a study done by Bulanda et al., 2014 the Crobach's alpha rating is .527 . The Cronbach's alpha for the Myths and Facts Measure for this study was .36 with all 7 items. This measure was adapted for the purpose of this study.

Personal Beliefs Survey (World Psychiatric Association, n.d): This measure was derived from a Canadian pilot project and was revised to fit the objectives of the study. This measure included 4 questions reflecting students' feelings about people with mental illness. There is no cited reliability or validity for the Personal Beliefs Survey. Cronbach's 
alpha for the Personal Beliefs for this study was .54 with all 4 items. (See Appendix H) This measure was adapted for the purpose of this study.

Ending the Silence Presentation: ETS is a 50-minute program designed for high school students. This presentation is devoted to giving students the chance to learn about mental illness through different contexts. The program engages students in a PowerPoint presentation, short videos, and personal testimony. Through the presentation students learn symptoms and signs of mental illness, and are given resources and information about how to help themselves, friends, or family members who may need support.

Program Evaluation: A short program evaluation form was developed for this study to assess if students believed there was any change in their knowledge or attitude about mental illness. It also asked students to disclose things they enjoyed and found beneficial from the presentation, and if there was anything they would change. (See Appendix I)

Demographic Questionnaire: The demographic questionnaire was given to gather basic demographic information such as age, grade, gender, ethnicity, and previous contact with people with mental illness. (See Appendix J)

\subsection{Procedures}

Students were given a consent form to give to their parents in order for their parents to allow their student to participate in the study. All students who brought back a signed consent form participated in the study. Students were also given a youth assent form to sign before the study (See Appendix E). Students who obtained parental consent and gave personal assent were given the $\mathrm{r}-\mathrm{AQ}$, the Myths and Facts Measure, the 
Personal Beliefs survey, and the demographic questionnaire before the ETS presentation. Participants then participated in the ETS program and were given the same measures directly following the presentation, excluding the demographic questionnaire and including presentation evaluation questions. The students were given a 6-week follow up assessment consisting of the same measures excluding the participation evaluation and the demographic questionnaire. After having obtained consent from a youth's parent/guardian, s/he was given an identification number based on the attendance sheet. This number was used to protect the youth's identity and was explained to the youth before the assessment. No names were required to complete the questionnaires. The identification numbers were only accessible to the principal investigator and the thesis advisor.

\subsection{Statistical Analysis}

One-way repeated measure ANOVA and paired-samples t-test analyses were utilized to evaluate the pre- and post-data. Independent sample t-test analyses were used to explore the relationship between students who have had previous contact with someone with mental illness or have a mental illness themselves and students who have not had previous contact with someone with mental illness or do not have a mental illness themselves and their baseline scores. 


\title{
CHAPTER 4
}

\section{RESULTS}

In order to analyze Hypotheses 1, 2, 3, and 4, one-way repeated measures ANOVAs were conducted with each of the three measures (Attribution Questionnaire (rAQ), Myths and Facts, and Personal Beliefs about Stigma) with the factor being time (pre-, post-, and 6-week follow-up). No outliers were found among the three measures. The alpha was set at .05 All indicated a significant main effect. Therefore, follow-up, paired sample $t$ tests were conducted to assess which means differed from each other. Four out of five of the hypotheses were supported in this study. The five hypotheses and the results of their analyses are below. Some students did not complete the assessment packs and therefore there is missing data in each analyses.

\author{
H1: The Ending the Silence program will decrease stigmatizing attitudes as \\ measured by the Attribution Questionnaire (r-AQ)- Short form for Children.
}

H2: The Ending the Silence program will improve the factual knowledge and understanding of mental illness as measured by the Myths and Facts Measure.

H3: The Ending the Silence program will improve positive personal beliefs about people with mental illness as measured by the Personal Beliefs scale.

H4: The positive changes in stigmatizing attitudes and knowledge and understanding of mental illness will be sustained in a 6-week follow up assessment. 
The means and standard deviations for the r-AQ scores are presented in Table 1. The results for this one-way repeated measures ANOVA indicated a significant time effect, Wilks' lambda $=.94, F(2,135)=4.29, p=.02$, multivariate eta squared $=.06$ Three pairwise comparisons among the pre-, post-, and 6-week follow-up means were then conducted. A marginally significant increase was found between the means of pre- and post-tests, $t(137)=-1.93, p=.056$. A significant mean increase was found between the pre-test and 6-week follow-up, $t(140)=-2.60, p=.011$. These results indicate the students' stigmatizing attitudes improved immediately after exposure to the presentation. However, there was an even more significant improvement in stigmatizing attitudes at the 6-week follow up. There was not a significant decrease in stigmatizing attitudes from post-test to 6-week follow up, $t(136)=-.817, p=.42$.

Table 1

Listwise Descriptives of the Attribution Questionnaire

\begin{tabular}{|l|l|l|l|l|l|}
\hline Measure & $\mathrm{n}$ & Mean & $\begin{array}{l}\text { Std. } \\
\text { Deviation }\end{array}$ & Minimum & Maximum \\
\hline Pre-AQ & 142 & 30.95 & 3.50 & 21 & 39 \\
\hline Post-AQ & 138 & 31.46 & 3.65 & 19 & 40 \\
\hline FU-AQ & 141 & 31.67 & 3.71 & 23 & 40 \\
\hline
\end{tabular}

The means and standard deviations for the Myths and Facts Measure are presented in Table 2. The results for this one-way, repeated measures ANOVA indicated a significant time effect, Wilks' lambda $=.57, F(2.135)=52.05, p<.0001$, multivariate eta squared $=.44$ 
Three pairwise comparisons among the means of pre-, post-, and 6-week follow up were conducted. A significant mean increase was found between the means of pre- and posttests, $t(137)=10.33, p<.0001$, and between pre-test and 6-week follow-up, $t(140)=$ $5.18, p<.0001$. These results indicate that the students' knowledge of mental illness facts improved after exposure to the presentation. It is also interesting to note that there was a significant decrease in the means from post- to 6-week follow-up $(t(136)=4.60, p$ $<.0001)$. The students may have been unable to retain the new information gained from the presentation represented by the results of the post-test, but were still more knowledgeable about mental illness than they were at baseline during the pre-test.

\section{Table 2}

Listwise Descriptives of The Myths and Facts Measure

\begin{tabular}{|l|l|l|l|l|l|}
\hline Measure & $\mathrm{n}$ & Mean & $\begin{array}{l}\text { Std. } \\
\text { Deviation }\end{array}$ & Minimum & Maximum \\
\hline Pre-MFM & 142 & 25.85 & 2.69 & 17 & 31 \\
\hline Post-MFM & 138 & 28.12 & 3.11 & 20 & 35 \\
\hline FU-MFM & 141 & 27.08 & 2.95 & 16 & 33 \\
\hline
\end{tabular}

The means and standard deviations for the Personal Beliefs scale are presented in Table 3. The results for this one-way, repeated measures ANOVA indicated a significant time effect, Wilks' lambda $=.86, F(2.132)=10.79, p<.0001$, multivariate eta squared $=.14$. Three pairwise comparisons among the means of pre-, post-, and 6-week follow-up were conducted. A significant mean increase was found between the means of pre- and posttests, $t(135)=-3.69, p<.0001$, and between pre-test and 6 week follow-up, $t(139)=-$ $4.18, p<.0001$. While there was a slight increase from post- to 6-week follow-up, this 
was not significant $(p=.235)$. These results indicate that students' personal beliefs about people with mental illness improved after exposure to the presentation.

Table 3

Listwise Descriptives of the Personal Beliefs Measure

\begin{tabular}{|l|l|l|l|l|l|}
\hline Measure & $\mathrm{n}$ & Mean & $\begin{array}{l}\text { Std. } \\
\text { Deviation }\end{array}$ & Minimum & Maximum \\
\hline Pre-Beliefs & 142 & 10.48 & 1.51 & 6 & 12 \\
\hline Post-Beliefs & 136 & 10.86 & 1.27 & 6 & 12 \\
\hline FU-Beliefs & 140 & 10.94 & 1.25 & 6 & 12 \\
\hline
\end{tabular}

H5: Students who know someone with mental illness or have a mental illness

themselves will report less stigma about mental illness, will have greater knowledge

about mental illness, and will report fewer negative personal beliefs about mental

illness as compared to students who do not have a personal experience with mental

illness.

Eighty-two percent of students reported that they knew someone with mental illness or had a mental illness themselves $(n=115)$. Three independent-samples $t$-tests were conducted to evaluate Hypothesis 5. The means and standard deviations of these measures for this analysis are presented in Table 4.

Table 4

Group Statistics

\begin{tabular}{|l|l|l|l|l|}
\hline \multicolumn{1}{|c|}{ Measure } & Mental Illness & \multicolumn{1}{|c|}{$\mathrm{n}$} & \multicolumn{1}{c|}{ Mean } & Std. Deviation \\
\hline Pre_AQ & Yes & 115 & 31.21 & 3.50 \\
\cline { 2 - 5 } & No & 25 & 30.20 & 3.57 \\
\hline Pre_MFM & Yes & 115 & 26.27 & 2.52 \\
\hline
\end{tabular}




\begin{tabular}{|l|l|l|l|l|}
\hline & No & 25 & 24.08 & 2.72 \\
\hline Pre_Beliefs & Yes & 115 & 10.59 & 1.49 \\
\cline { 2 - 5 } & No & 25 & 10.04 & 1.54 \\
\hline
\end{tabular}

The results of the independent-samples $t$-test for the r-AQ Stigma measure $(t$ $(138)=1.31, p=.192)$ and the Personal Beliefs measure $(t(138)=1.66, p=.099)$, were non-significant. However, the test was significant for the Myths and Facts measure $(t$ $(138)=3.89, p<.0001)$. These results indicate that previous contact with someone with mental illness or having a mental illness did not result in a less stigmatizing attitude or more positive personal beliefs at baseline. However, these results do reflect that previous contact or having a mental illness did contribute to higher baseline knowledge of mental illness facts.

\subsection{Qualitative and Program Evaluation Results}

The students were asked at the pre-test, post-test, and follow-up assessment to provide their definition of mental illness. A content analysis was conducted to identify respondent's themes and trends in participants responses. At the pre-test the common responses were: "not the same as normal people" (15.5\%) "not functioning properly" (16.9\%) and "chemical or genetic" (14.0\%). At the post-test the most common responses were: "feeling or acting differently (15.5\%);" "a genetic or chemical disorder (14.7\%);" and "unable to function properly (18.3\%)", and "illness of the brain" (13.3\%). At the follow-up, the most common answers were: "acting or behaving differently" $(22.5 \%)$, "not functioning at their best or as well as others" (15.5\%); and "illness of the brain" $(18.3 \%)$ 
The students were asked at the post-test to complete a program evaluation. They were asked "What part of the presentation had the most benefit for you?" The majority of students identified that the speakers sharing their stories was the most beneficial to them. The students were also asked, "What part of the presentation would you improve?" The majority of participants said that they would improve "the PowerPoint, "have more speakers, "and "make slides more entertaining."

Additionally, the students were asked, "Has your knowledge about mental illness improved as a result of this presentation?" $52.1 \%(n=74)$ answered that it "somewhat" improved their knowledge, $38 \%(n=54)$ answered that it "considerably" improved their knowledge, and 6.3\% $(n=9)$ answered "not at all". Students were also asked, "has this presentation changed your attitude towards people with mental illness?" $61.3 \%(n=87)$ of students responded that their attitude had become more positive, $34.5 \%(n=49)$ reported that their attitude hadn't changed, and .7\% $(n=1)$ reported that their attitude had become more negative. Lastly, students were asked, "Do you think that you will now act differently towards people with a mental illness as a result of this presentation?" $50 \%$ (n $=71)$ of students responded "yes", $31.7 \%(n=45)$ responded "probably not", and $14.8 \%$ $(n=21)$ responded, "I don't know." 


\section{CHAPTER 5}

\section{DISCUSSION}

The need for mental health education programs has become more and more apparent to school systems. Schools are beginning to respond to this need and are able to see that education is crucial for creating the progress towards eradicating stigma. The results of this current research study are consistent with findings from previous research evaluating other youth-based programs (Pinfold et al., 2003; Spagnolo , Murphy, \&Librera, 2008). Spagnolo et al. (2008) found similar results when examining the effectiveness of public education programs on the attitudes of high school students towards people with mental illness. Spagnolo et al. (2008) found that after viewing the presentations, students reported less stigmatizing attitudes towards people with mental illness. In the research done by Pinfold et al. (2003), the researchers assessed the effectiveness of an intervention with the intention of increasing students' understanding of mental health and to challenge negative stereotypes. They found that educational workshops could have positive changes in students' attitudes towards people with mental illness.

It was hypothesized that students' stigmatizing attitudes would be improved by exposure to the Ending the Silence program. This hypothesis was supported, which is consistent with previous research conducted by Pinfold et al. (2003). The hypothesis may be supported due to the focus of the ETS program on stigma, and clearly defining stigma for the students. The ETS program is primarily aimed at decreasing stigma through education and contact. The improvement in stigmatizing attitudes was even more significant at the 6-week follow-up. This finding is different than other studies. In 
previous research, Pinfold et al. (2013) found that scores decreased at the follow-up, in the present study the students' attitudes continued to improve over the 6-week period. This may also be due to the ETS program encouraging students to continue the conversation about mental illness with their peers, their parents, and their teachers. ETS uses relatable examples that may have prompted students to continue their education on their own. The schools chosen for the presentation showed interest and commitment to education and awareness, and the teachers from each class may have aided in students' continued improvement in attitudes towards mental illness. It was observed by the principal researcher after conducting the post-test evaluation that teachers continued to engage in discussion answering questions and providing clarification for students and this may have consolidated and supported the learning from the program.

Another hypothesis was that the students' knowledge of mental illness facts would improve after exposure to the program. This hypothesis was also supported by prior research. The students' knowledge of mental illness did slightly decrease from posttest to 6-week follow-up, which may mean that students' knowledge initially did improve but that students may have had difficulty retaining the information over the 6-week period before the follow up. This may be due to the normal developmental stage of teenagers, or due to a lack of memorable examples from the presentation.

The third hypothesis was that students' personal beliefs about mental illness would improve after exposure to the presentation. This hypothesis was supported, which is consistent with previous research by Chandra and Minkovitiz (2007) who found that students who had limited or inaccurate information regarding mental health tended to have more negative attitudes and beliefs. A possible explanation for these results could be 
due to the contact provided through the ETS program. Having speakers who live with mental illness come in and share their story could have affected students' personal beliefs.

The fourth hypothesis was that these improvements would be sustained over a 6week follow-up period. These results were supported. Students' scores improved from pre-test to follow-up on all measures. One reported study in the literature (Pinfold et al., 2003 ) conducted a follow-up evaluation at the 6-month mark and found that scores had dropped from the one-week follow up but still higher than the baseline measurement. The findings in this study are an important contribution to the research, as follow-up assessments have not been conducted showing sustainability of programs in previous research. The sustained improvements may be contributed to the follow-up discussions conducted in the classrooms as well as presenting relatable material.

Lastly, it was hypothesized that students who had previous contact with someone with mental illness or had a mental illness would be less stigmatizing, more informed, and have more positive beliefs at the pre-test than those who had reported no previous contact with someone with mental illness or no mental illness themselves. This hypothesis was supported in regard to students' factual knowledge about mental illness. Students who self-reported knowing someone with mental illness or having a mental illness themselves did not have fewer stigmatizing attitudes or more positive beliefs at the pre-test but did have more knowledge about mental illness than the students who reported not having any previous contact with someone with mental illness or not having a mental illness themselves. An explanation for these results may be that students who have had contact with someone living with mental illness or have a mental illness may understand 
the facts about mental illness but may still feel shame or stigma towards their own mental illness or other people with mental illness. Students were asked to self-report their contact with someone with mental illness or personal mental illness during the pre-test portion this may have led to their incorrectly reporting contact due to lack of knowledge or understanding of the definition of mental illness.

\subsection{Limitations}

Despite the positive implications of this study, there are some limitations to this study worth noting. For example, some of the students were unable to view the whole presentation due to the length of the class period, and some got the whole version but presenters reported rushing through the presentation due to the bell schedule at the different high schools. That may have had an effect on students' responses on the measures. Second, the measures were adapted from measures used with adult populations resulting in low reliability of the measures used. In the demographic questionnaire students were asked to self-report whether they themselves had a mental illness or they knew someone with a mental illness and "self or others" were combined so there is not way to be sure what percentage of students self-identified as having a mental illness versus having experience with others who had a mental illness. There may be a difference between the two groups but due to how the question was stated it is difficult to know. Participants were asked to self-report their experience with mental illness during the pretest demographic questionnaire, this may have contributed to students reporting falsely due to confusion and/or varied definitions of what mental illness is. Lastly, working with an adolescent population there may have been increased social desirability at play due to basic understanding of socially acceptable answers to some of the questions on the 
measures. The principal researcher did speak to this and stressed the importance of honest answers during the gathering of the data., But due to the developmental stage of the participants; it is possible that social desirability may have contributed to the results.

\subsection{Implications For Stigma Reduction Programs Aimed at Youth}

The findings in this study have implications for other stigma reduction programs aimed at youth. Stigma or mental health education programs aimed at youth may benefit from more opportunities for students to hear real-life examples and narrative from presenters. Students overwhelmingly reported that the most beneficial part of the program was hearing the speaker's story. With that said, it may be effective for presenters or people sharing their stories of living with mental illness to be a more relatable age for the students. In this study, there were two presenters who both shared stories of living with mental illness. One presenter was a young man, and the other was an older woman. In the qualitative analysis the students only mentioned the narrative of the young man, while both the young man and older woman shared stories of living with mental illness. It appeared that students were either only able to recall the story from the young man, or students were not as affected by the woman's story. It may be effective to make use of more examples of celebrities living with mental illness. Based on observations during data collection it was apparent that students had a reaction to learning about different celebrities who had mental illness. It appeared to normalize each diagnosis for the students and reduce some of the negative beliefs students may have held about the diagnosis when they found out celebrities they enjoy, or even idolize, live with a particular mental illness. Mental health education programs that incorporate more firstperson narratives from young people living with mental illness, as well as examples of 
public celebrities with mental illness, may be useful approaches at challenging stereotypes and inaccurate information surrounding people with mental illness.

\subsection{Implications for Future Research}

The findings of this study have research implications worth mentioning. It is important for there to be more program evaluations of not just stigma-based programs, but all programs aimed at youth to understand what works well for that population. It may be effective for future researchers to have a control group who are not exposed to the presentation and to look at the differences in scores between students who were exposed to the presentation and students who did not receive any intervention. As mentioned previously, it may be beneficial to administer a social desirability scale following the assessments in order to assess students' likelihood to answer in socially acceptable ways.

In regards to mental illness stigma, this study sheds light on the fact that young people need exposure to and education on mental illness. Interventions such as educational presentations, hearing real life narratives from people living with mental illness, or even class discussions, can change the way students think and feel about others. Stigma reduction programs need to continue to be developed and evaluated in order to continue to improve the dialogue about mental illness with our youth. An important future direction for stigma research is to develop scales and measures that are geared towards our youth. There needs to be an improvement in the development of research tools that are easier for students to understand, and demonstrate sound reliability and construct validity across ages, cultures, and gender.

\subsection{Conclusion}

The beliefs and attitudes people have about mental illness come from many different sources, including family, media, peers, and personal experience. With the many 
different channels of information, it can be difficult for people to obtain accurate information about mental illness and those who live with it. The narrative surrounding mental illness is changing. It is becoming more positive, it is becoming less taboo, and it is our youth that will contribute to this continued change. Through the development of the research questions and hypotheses, consideration of NAMI and its objectives and goals during the development of measures used in this study the principal researcher gathered data from different high school campuses, and through detailed data analysis was able to find that the ETS program was successful in decreasing stigmatizing attitudes, improving overall knowledge about mental illness, and improving students' personal beliefs regarding mental illness. Furthermore, the program was able to deliver a message that was sustainable over a 6-week period. Adolescence is by nature a chaotic and complex time in a person's life, but dealing with mental illness on top of that can create unpredictable difficulties. Reducing the impact of stigma can ultimately increase opportunities to help individuals with mental illness lead more fulfilling and satisfying lives (Vogel et al., 2013). Programs like ETS do not just aim to improve the understanding of mental illness, but their overall goal is to create a more accepting and safe environment for all students. 


\section{REFERENCES}

Brockington, I.F., Hall, P. \& Levings, J. (1993). The community's tolerance of the mentally ill. British Journal of Psychiatry, 162, 93-99. doi: 10.1192/bjp.162.1.93

Bulanda, J. J., Bruhn, C., Byro-Johnson, T., \& Zentmyer, M. (2014). Addressing mental health stigma among young adolescents: Evaluation of a youth-led approach. Health and Social Work, 39, 73-80. doi: 10.1093/hsw/hlu008

California Department of Education. (2012). Health education content standards.

Centers for Disease Control and Prevention. (2011). Stigma and illness. Retrieved from http://www.cdc.gov/mentalhealth/about_us/stigma-illness.htm.

Centers for Disease Control and Prevention. (2013). Stigma of mental illness. Retrieved from http://www.cdc.gov/mentalhealth/data_stats/mental-illness.htm

Chandra, A. \& Minkovitz, C. S. (2007). Factors that influence mental health stigma among $8^{\text {th }}$ grade adolescents. Journal of Youth Adolescence, 36, 763-774. doi: $10.1007 / \mathrm{s} 10964-006-9091-0$

Corrigan, P.W., Edwards, A., Green, A., Diwan, S.E., \& Penn, D.L. (2001). Prejudice, social distance, and familiarity with mental illness. Schizophrenia Bulletin, 27, 219-226. Retrieved from:

http://eds.a.ebscohost.com.ezproxy.lib.calpoly.edu/ehost/pdfviewer/pdfviewer?vi $\mathrm{d}=11 \&$ sid=9986e6f9-2309-404f-9346-

2e2e13b73879\%40sessionmgr4005\&hid $=4110$

Corrigan, P.W. \& Watson, A.C. (2002). The paradox of self-stigma and mental illness. Clinical Psychology Science Practice, 9, 35-53. doi: 10.1093/clipsy.9.1.35

Corrigan, P.W., Markowitz, F. E., Watson, A., Rowan, D., \& Kubiak, M. (2003). An attribution model of public discrimination towards persons with mental illness. Journal of Health and Social Behavior, 44, 162-169. Retrieved from: http://www.jstor.org/stable/1519806.

Corrigan, P.W., Kerr, A., \& Knudsen, L. (2005). The stigma of mental illness: Explanatory models and methods for change. Applied and Preventive Psychology, 11, 179-190. doi: 10.1016/j.appsy.2005.07.001

Corrigan, P.W. \& Shapiro, J.R. (2010). Measuring the impact of programs that challenge the public stigma of mental illness. Clinical Psychology Review, 30, 907-922. doi: 10.1016/j.cpr.2010.06.004

Couture, S. M. \& Penn, D.L. (2003). Interpersonal contact and the stigma of mental illness: A review of the literature. Journal of Mental Health, 12, 291-305. doi: $10.1080 / 09638231000118276$ 
Essler, V. Arthur, A., \& Stickley, T. (2006). Using a school-based intervention to challenge stigmatizing attitudes and promote mental health in teenagers. Journal of Mental Health, 15, 243-250. doi: 10.1080/09638230600608669

Goffman, E. (1963). Stigma and Social Identity. Stigma: Notes on the management of spoiled identity (1-40). New York, NY: Simon \& Schuster.

Gostin, L. O. (2008). 'Old' and 'new' institutions for persons with mental illness: Treatment, punishment or preventative confinement? Journal of the Royal Institute of Public Health, 122, 906-913. doi:10.1016/j.puhe.2007.11.003

Han, S. S., \& Weiss, B. (2005). Sustainability of teacher implementation of school-based mental health programs. Journal of Abnormal Child Psychology, 33, 665-679. doi: 10.1007/s10802-005-7646-2

Karch, D. L., Logan, J., McDaniel, D.D., Floyd, C. F., \& Vagi, K.J. (2013). Precipitating circumstances of suicide among youth aged 10-17 years by sex: Data from the nation death reporting system, 16 states, 2005-2008. Journal of Adolescent Health, 53, S51-S53. doi: 10.1016/j.jadohealth.2012.06.028

Kleinman, A. \& Hall-Clifford, R. (2009). Stigma: A social, cultural and moral process. Journal of Epidemiology and Community Health, 63, 418-419. doi: 10.1136/jech.2008.084277

Koller, M., \& Stuart, H. (2011). Opening minds university: Results of a contact-based anti-stigma intervention. Mental Health Commission of Canada. Retrieved from: http://www.mentalhealthcommission.ca/English/system/files/private/Stigma_Ope ning_Minds_at_University_ENG_0.pdf

Levine, J. M. (2015). Historical notes on restraint reduction: The legacy of Dr. Philippe Pinel. Journal of American Geriatrics Society, 44, 1130-1133. doi: 10.1111/j.1532-5415.1996.tb02956.x

Lindsay, S. \& Edwards, A. (2013). A systematic review of disability awareness interventions for child and youth. Disability \& Rehabilitation, 35, 623-646. doi: $10.3109 / 09638288.2012 .702850$

Lindsey, C. R. \& Kalafat, J. (1998). Adolescents' views of preferred helper characteristics and barriers to seeking help from school-based adults. Journal of Educational and Psychological Consultation, 9, 171-193. Retrieved from: http://eds.a.ebscohost.com.ezproxy.lib.calpoly.edu/ehost/pdfviewer/pdfviewer?sid $=9986 \mathrm{e} 6 \mathrm{f} 9-2309-404 \mathrm{f}-9346$ 2e2e13b73879\%40sessionmgr4005\&vid $=16 \&$ hid $=4110$ 
Link, B. G., Struening, E. L., Neese-Todd, S., Asmussen, S., \& Phelan, J.C., (2001). Stigma as a barrier to recovery: The consequences of stigma for the self-esteem of people with mental illnesses. Psychiatric Services, 52, 1621-1626.

Major, B \& O’Brien, L.T. (2005). The social psychology of stigma. Annual Review of Psychology, 56, 393-421. doi: 0.1146/annurev.psych.56.091103.070137

Martin, J. K., Pedcosolido, B.A., Olafsdottir, S., \& Mcleod, J. D. (2007). The construction of fear: Americans' preferences for social distance from children and adolescents with mental health problems. Journal of Health and Social Behavior 2007, 48, 50-67. Retrieved from: http://www.jstor.org/stable/27638690

Morgan, A. J. \& Jorm, A. F. (2009). Recall of news stories about mental illness by Australian youth: Associations with help-seeking attitudes and stigma. The Royal Australian and New Zealand College of Psychiatrists, 28, 866-872. doi: 10.1080/00048670903107567

Moses, T. (2010). Adolescent mental health consumers' self-stigma: Associations with parents' and adolescents' illness perceptions and parental stigma. Journal of Community Psychology, 38, 781-798. doi: 10.1002/jcop.20395

Mullins, J. (2012). The power of the media to shape perceptions of mental illness. Mental Health Practice, 17, 34-35. Retrieved from: http://journals.rcni.com/doi/pdfplus/10.7748/mhp2014.05.17.8.34.e812

National Alliance on Mental Illness. (2010). Mental health facts: Children and teen. Retrieved from: http://namimd.org/uploaded_files/475/Children-MH-FactsNAMI.pdf

National Alliance on Mental Illness (2013) Mental illness facts and numbers. Retrieved from: http://www2.nami.org/factsheets/mentalillness_factsheet.pdf

National Alliance on Mental Illness. (2014). NAMI ending the silence outreach strategies guide. Retrieved from:

http://www2.nami.org/Content/NavigationMenu/Intranet/Ending_the_Silence3/E TSOutreachStrategiesGuide.pdf

National Alliance on Mental Illness (2015). ETS 10 key messages. Retrieved from: http://namigo.org/wpcontent/uploads/sites/108/2015/09/ETS_About_the_program.pdf

Parry, M.S. (2006). Dorothea Dix (1802-1887). Journal of Public Health, 96, 624-625. doi: 10.2105/AJPH.2005.079152

Pinfold, V., Toulmin, H., Thornicroft, G., Huxley, P., Farmer, P., \& Graham, T. (2003). Reducing psychiatric stigma and discrimination: Evaluation of educational 
interventions in UK secondary schools. British Journal of Psychiatry, 182, 342346. doi: 10.1192/bjp.182.4.342

Pinto, M. D., Hickman, R., Logsdon, C. M., \& Burant, C. (2012). Psychometric evaluation of the revised attribution questionnaire (r-Aq) to measure mental illness stigma in adolescents. Journal of Nurs Meas. 20, 47-58. Retrieved from: http://www.ncbi.nlm.nih.gov/pmc/articles/PMC3506425/pdf/nihms419443.pdf

Rüsch, N., Angermeyer, M. C., \& Corrigan, P. W. (2005) Mental illness stigma: Concepts, consequences, and initiatives to reduce stigma. European Psychiatry, 20, 529-539. doi: 10.1016/j.eurpsy.2005.04.004

Sakellari, E., Leino-Kilpi, H., \& Kalokerinou-Anagnostopoulou, A. (2011). Educational interventions in secondary education aiming to affect pupils' attitudes towards mental illness: A review of the literature. Journal of Psychiatric and Mental Health Nursing, 18, 166-176. doi: 10.1111/j.1365-2850.2010.01644.x

Scheyett, A. M. (2005). The mark of madness: Stigma, serious mental illnesses, and social work. Social Work in Mental Health: The Journal of Behavioral and Psychiatric Social Work, 3, 79-97

Spangnolo, A. B., Murphy, A. A., \& Librera, L. (2008). Reducing stigma by meeting and learning from people with mental illness. Psychiatric Rehabilitation Journal, 31, 186-193. doi: 10.2975/31.3.2008.186.193

Stuart, H. (n.d.). Measurement toolkit: Global anti-stigma program world psychiatric association Canadian pilot project. Retrieved from:

http://post.queensu.ca/ hh11/assets/applets/Stigma_Toolkit.pdf

Stuart, H. (2006). Reaching out to high school youth: The effectiveness of a video-based anti stigma program. Canadian Journal of Psychiatry, 51, 647-653. Retrieved from:

http://eds.b.ebscohost.com.ezproxy.lib.calpoly.edu/ehost/pdfviewer/pdfviewer?sid $=19 f 80772-2 \mathrm{a} 5 \mathrm{~b}-42 \mathrm{~b} 6-824 \mathrm{~d}-7 \mathrm{c} 98 \mathrm{eb} 9 \mathrm{ffdff} \%$ 40sessionmgr $198 \& \mathrm{vid}=22 \& \mathrm{kid}=117$

Substance Abuse and Mental Health Services Administration. (2007). What a difference a friend makes (National mental health anti-stigma campaign). Retrieved from: http://www.sprc.org/library_resources/items/what-difference-friend-makesnational-mental-health-anti-stigma-campaign

United States Department of Justice. (2009). A guide to disability right laws. Retrieved from:http://www.ada.gov/cguide.htm

United States Department of Justice, Civil Rights Division. (n.d.). Introduction to the ADA. Retrieved from: http://www.ada.gov/ada_intro.htm 
Vogel, D.L., Wade, N., \& Haake, S. (2006). Measuring the self-stigma associated with seeking psychological help. Journal of Counseling Psychology, 53, 325-337. doi: 0.1037/0022-0167.53.3.325

Vogel, D.L., Wade, N., \& Hackler, A. (2007). Perceived public stigma and the willingness to seeking counseling: The mediating roles of self-stigma and attitudes towards counseling. Journal of Counseling Psychology, 54, 40-50. doi: 10.1037/0022-0167.54.1.40

Vogel, D. L., Bitman, R. L., \& Hammer, J. H., Wade, N. G. (2013). Is stigma internalized? The longitudinal impact of public stigma on self-stigma. Journal of Counseling Psychology, 60, 311-316. doi: 10.1037/a0031889

Wahl, O.F. (1999). Mental health consumers' experience of stigma. Schizophrenia Bulletin, 25, 467-478. Retrieved from:

http://eds.b.ebscohost.com.ezproxy.lib.calpoly.edu/ehost/pdfviewer/pdfviewer?sid $=19 f 80772-2 \mathrm{a} 5 \mathrm{~b}-42 \mathrm{~b} 6-824 \mathrm{~d}-7 \mathrm{c} 98 \mathrm{eb} 9 \mathrm{ffdff} \% 40$ sessionmgr $198 \& \mathrm{vid}=49 \& \mathrm{hid}=117$

Wahl, O., Hanrahan, E., Karl, K., Lasher, E., \& Swaye, J. (2007). The depiction of mental illness in children's television programs. Journal of Community Psychology, 35, 121-133. doi: 10.1002/jcop.20138

Watson, A. C., Otey, E., Westbrook, A. L., Gardner, A. L., Lamb, T. A., Corrigan, P. W., \& Fenton, W. S. (2004). Changing middle schoolers' attitudes about mental illness through education. Schizophrenia Bulletin, 30, 563-572. Retrieved from: http://eds.b.ebscohost.com.ezproxy.lib.calpoly.edu/ehost/pdfviewer/pdfviewer?sid $=19 f 80772-2 \mathrm{a} 5 \mathrm{~b}-42 \mathrm{~b} 6-824 \mathrm{~d}-7 \mathrm{c} 98 \mathrm{eb} 9 \mathrm{ffdff} \% 40$ sessionmgr $198 \& \mathrm{vid}=53 \& \mathrm{hid}=117$ 


\section{APPENDICES}

\section{APPENDIX A}

\section{ETS 10 Key Messages}

1. Mental illness is a medical illness like any other illness

2. Mental illness is not anyone's fault or something to be ashamed of

3. There are specific, observable early warning signs of mental illness. You can help yourself and your friends by being aware of these signs and making sure treatment is sought as soon as possible

4. Proper treatment is necessary in order to achieve recovery

5. The earlier you seek treatment, the better

6. Acceptance is an important part of recovery

7. Recovery is possible

8. There is hope

9. Reducing stigma is essential to reduce the gap between the onset of symptoms and when an individual seeks treatment

10. Although it may feel like it sometimes, you are never alone and there are many resources you can turn to for support and information. 
APPENDIX B

\section{Health Education Content Standards}

\section{Standard 1: Essential Concepts}

1.7M Analyzes signs of depression, potential suicide, and other self-destructive behaviors 1.10M Identify warning signs for suicide

\section{Standard 2: Analyzing Influences}

2.1M Analyze the internal and external issues related to seeking mental health assistance

\section{Standard 3: Accessing Valid Information}

3.1M Access school and community resources to help with mental, emotional, and social health concerns

3.2M Evaluate the benefits of professional services for people with mental, emotional, or social health conditions

\section{Standard 4: Interpersonal Communication}

4.1 Seek help from trusted adults for oneself or a friend with an emotional or social health problem

4.2M Discuss healthy ways to respond when you or someone you know is grieving

\section{Standard 5: Decision Making}

5.2M Compare various coping mechanisms for managing stress 
5.3M Analyze situations when it is important to seek help with stress, loss, and unrealistic body image, and depression

\section{Standard 6: Goal Setting}

6.1M Evaluate how preventing and managing stress and getting help for mental and social problems can help a person achieve short- and long-term goals

\section{Standard 7: Practicing Health-Enhancing Behaviors}

7.2M Practice effective coping mechanisms and strategies for managing stress

7.3M Discuss suicide-prevention strategies

\section{Standard 8: Health Promotion}

8.1M Support the needs and rights of others regarding mental and social health 
APPENDIX C

\section{Letters of Support}

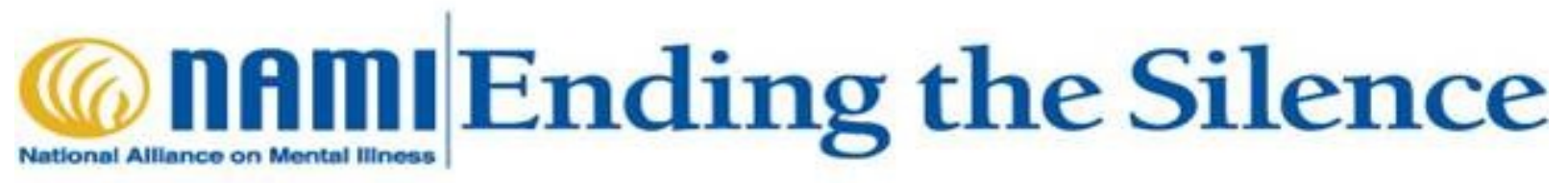

To Whom It May Concern:

I am writing this letter on behalf of Sarah Taniyama in support of her participation as a program evaluator for the National Alliance of Mental Illness's Ending the Silence program. We welcome Miss Taniyama's contribution to our project, and look forward to viewing and utilizing her results. Please feel free to contact me with any questions.

Joseph A. Johnson

Coordinator

Ending the Silence

National Alliance on Mental Illness

San Luis Obispo County 


\section{SAN LUIS OBISPO HIGH SCHOOL \\ 1499 San Luis Drive, San Luis Obispo, California 93401-3099 \\ Phone (805) 596-4040 \\ FAX (805) 542-9075 \\ Voice Mail (805) $596-4050$

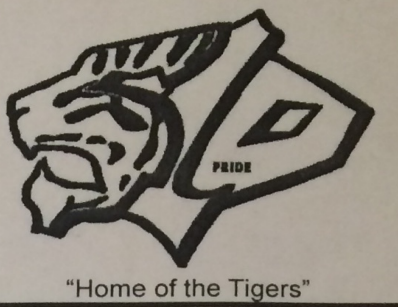

To Whom It May Concern:

I am writing this letter on behalf of Sarah Taniyama in support of her participation as a program evaluator for the National Alliance of Mental Illness's Ending the Silence program. The students at San Luis Obispo High School do not need parental consent to participate in the Ending the Silence program, as it is a natural part of the academic curriculum. Miss Taniyama's participation in evaluating the program is welcomed. Please feel free to contact me with any questions.

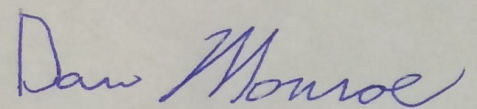

Dan Monroe

San Luis Obispo High School

Health Science Teacher

Varsity Girls' Basketball Coach

Varsity Softball Coach 
To Whom It May Concern:

I am writing this letter on behalf of Sarah Taniyama in support of her participation as a program evaluator for the National Alliance of Mental Illness's Ending the Silence program. The students at Mission College Preparatory High School do not need parental consent to participate in the Ending the Silence program, as it is a natural part of the academic curriculum. Miss Taniyama's participation in evaluating the program is welcomed, and Mission Preparatory High School would prefer the option for parents of students participating in the program to opt out of their student participating in the evaluation conducted by Miss Taniyama. Please feel free to contact me with any questions.

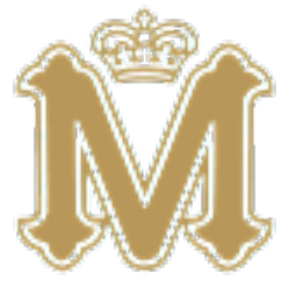

\section{Sylvan Levin}

Dean of Faculty 682 Palm Street San Luis Obispo, CA 93401

P: 805.543.2131 x 418 F: 805.543 .4359

Scholarship - Inspiration - Leadership 


\section{MORRO BAY HIGH SCHOOL}

A CALIFORNIA DISTINGUISHED SCHOOL

A NATIONAL BLUE RIBBON SCHOOL

235 Atascadero Road Morro Bay, CA 93442 Phone: (805)771-1845 Fax: (805) 772-5944 http://mbhs.slcusd.org

March 4, 2016

To Whom It May Concern:

I am writing this letter on behalf of Sarah Taniyama in support of her participation as a program evaluator for the National Alliance of Mental Illness's Ending the Silence program. The students at Morro Bay High School do not need parental consent to participate in the Ending the Silence program, as it is a natural part of the academic curriculum. Miss Taniyama's participation in evaluating the program is welcomed. Please feel free to contact me with any questions.

Sincerely,

Meredith Salio

Teacher, Morro Bay High School

msalio@slcusd.org

APPENDIX D

\section{Parental Permission Form}


An Evaluation of the Effectiveness of the National Alliance on Mental Illness (NAMI) Ending the Silence (ETS) Program

You are being asked to provide permission for your child/children to participate in the National Alliance on Mental Illness (NAMI) Ending the Silence (ETS) Program evaluation study. This is being conducted as Master's Thesis research in Psychology and Child Development at Cal Poly by Sarah Taniyama, under the supervision of Dr. Lisa Sweat. The purpose of this study is to evaluate the effectiveness of the Ending the Silence program on increasing youths' accurate knowledge about mental illness, reducing the stigma related to mental illness, and its ability to deliver a message of hope and recovery to young people dealing with mental illness in some way in their lives. Your child is being ask to complete questionnaires before, immediately after, and 4-6 weeks after viewing the "End the Silence" program in school. Their participation would take a total of approximately 30 minutes.

Your student's participation in this program evaluation is completely voluntary, and they may discontinue their participation at any time. They can also choose not to answer any questions that they would prefer not to answer. Whether or not your student participates in this evaluation will have no effect on his/her academic standing.

There are no risks anticipated with participation in this study. However, your child's teacher and the researcher will be available to address any concerns that may arise. Your child's participation in this study will be confidential, however, if it is determined that they are in danger of being abused or neglected, or they are at risk of hurting themselves or others, then confidentiality will be broken and the appropriate authorities will be notified. Otherwise, their name(s) will not be used in any reports of this research without permission.

If you would like more information about the study or would like to learn the results of the study when they are available, please feel free to email Sarah Taniyama, sarahtaniyama7@gmail.com, or faculty committee chair, Dr. Lisa Sweatt, 1sweatt@calpoly.edu. If you have concerns regarding the manner in which the study is conducted, you may contact Dr. Steve Davis, Chair of the Cal Poly Human Subjects Committee, at 805-756-2754, sdavis@calpoly.edu, or Dr. Wendt, Dean of Research, at 805-756-1508, dwendt@,calpoly.edu.

If you agree to allow your child to voluntarily participate in this study as described, please indicate your permission by signing below and returning a signed copy of this form to school via your child/children. Please retain a copy of this form for your reference, and thank you for considering your child's/children's participation.

Name(s) of Child/Children:

Signature of Parent/Guardian

Date

APPENDIX E

Youth Assent Form 


\section{INFORMED ASSENT FOR YOUTH TO PARTICIPATE IN NATIONAL ALLIANCE ON MENTAL ILLNESS ENDING THE SILENCE PROGRAM EVALUATION STUDY}

An evaluation of the Ending the Silence (ETS) Program is being conducted by Sarah Taniyama, a Psychology Master's student at Cal Poly San Luis Obispo, under the supervision of Dr. Lisa Sweatt. The purpose of this study is to better understand how the ETS program impacts how students feel and think about mental illness, and their opinion of the ETS program. We want to understand the effectiveness of ETS at meeting its objectives and goals.

You are being asked to take part in this study by completing a series of questions before the ETS program, after the ETS program, and 3-4 weeks following the ETS program. Your participation will take approximately 5-10 minutes of 3 separate occasions. You will complete these questionnaires in the class you will receive the ETS presentation. You will be asked questions about how you feel about a new student with mental illness, other people with mental illness, and questions regarding information about mental illness you will learn in the ETS program. Information regarding your gender, age, and ethnic background will also be gathered. Please be aware that you are not required to participate in this study and you may discontinue your participation at any time without penalty. You also do not have to answer any questions you chose not to answer. Your choice to participate or not participate in this study will not positively or negatively affect your participation in your class.

Your confidentiality will be protected. Students who choose to participate in this evaluation will be assigned an identification number; your name will not appear on any of the questionnaires. This identification number/name list will only be available to the principle investigator, Sarah Taniyama and Dr. Lisa Sweatt, and will be kept in a secure, locked cabinet. Your name will not be used in any reports of this research without permission.

The possible risks associated with your participation in this study are minimal. The principal investigator and school faculty will be present during administration of the questionnaires in order to answer any questions you might have. However, if you should become distressed during of after completing the questionnaires, you will be referred to the appropriate school staff member and/or school counselor. The information gained through your participation in this study will greatly help in the improvement of the ETS program, which ultimately will assist other students and their families.

If you have any questions regarding this study or would like to be informed of the results when the study is completed, please feel free to contact Sarah Taniyama, at 858-4424549 , or Dr. Lisa Sweatt, Ph.D. at 805-756-6123. If you have any concerns regarding the manner in which the study is conducted you may contact Dr. Steve Davis, Chair of the Cal Poly Human Subjects Committee at 805-756-2754, sdavis@calpoly.edu or Dr. Wendt, Dean of Research, at 805-756-1508,dwendt@calpoly.edu. 
If you agree to voluntarily participate in this research study as described, please indicate your agreement by signing below. Please keep one copy of this form for your reference. Thank you for your participation in this research.

Name of Youth Participant:

Please print name

Signature of Youth Participant

Date

Signature of Researcher

Date

Sarah Taniyama

Psychology \& Child Development Department

Psychology Masters Student

California Polytechnic State University, San Luis Obispo

APPENDIX F

Revised Attribution Questionnaire 
ID Number

Date

\section{PLEASE READ THE FOLLOWING STATEMENT ABOUT CHARLIE.}

Charlie is a new student in your class. Before Charlie's first day, your teacher explained that Charlie is mentally ill and is transferring from a special school.

\begin{tabular}{|c|c|c|c|c|c|}
\hline & $\begin{array}{c}\text { Strongly } \\
\text { Agree }\end{array}$ & Agree & Unsure & Disagree & $\begin{array}{l}\text { Strongly } \\
\text { Disagree }\end{array}$ \\
\hline $\begin{array}{l}\text { 1. It is not } \\
\text { the student's } \\
\text { fault if } \\
\text { he/she has a } \\
\text { mental } \\
\text { illness }\end{array}$ & & & & & \\
\hline $\begin{array}{l}\text { 2. I feel sorry } \\
\text { for the new } \\
\text { student }\end{array}$ & & & & & \\
\hline $\begin{array}{l}\text { 3. The new } \\
\text { student } \\
\text { makes me } \\
\text { angry }\end{array}$ & & & & & \\
\hline $\begin{array}{l}\text { 4. I would } \\
\text { help the new } \\
\text { student }\end{array}$ & & & & & \\
\hline $\begin{array}{l}\text { 5. The new } \\
\text { student } \\
\text { should be in } \\
\text { a mental } \\
\text { hospital }\end{array}$ & & & & & \\
\hline $\begin{array}{l}\text { 6. The new } \\
\text { student is not } \\
\text { dangerous }\end{array}$ & & & & & \\
\hline $\begin{array}{l}\text { 7. I am } \\
\text { scared of the } \\
\text { new student }\end{array}$ & & & & & \\
\hline $\begin{array}{l}\text { 8. I will try } \\
\text { to stay away } \\
\text { from the new } \\
\text { student }\end{array}$ & & & & & \\
\hline
\end{tabular}

APPENDIX G

Mental Health Facts 
The following statements are common beliefs about mental illness. Mark the answer that is most true for you.

\begin{tabular}{|l|l|l|l|l|l|}
\hline $\begin{array}{l}\text { Agree } \\
\text { illness is } \\
\text { contagious }\end{array}$ & & Agree & Unsure & Disagree & $\begin{array}{c}\text { Strongly } \\
\text { Disagree }\end{array}$ \\
\hline $\begin{array}{l}\text { 2. People } \\
\text { with mental } \\
\text { illness }\end{array}$ & & & & \\
cannot work & & & & \\
\hline $\begin{array}{l}\text { 3. You can } \\
\text { recover from }\end{array}$ & & & & \\
mental & & & & \\
illness & & & & \\
\hline $\begin{array}{l}\text { 4. There are } \\
\text { warning }\end{array}$ & & & & \\
signs to help & & & & \\
someone & & & & \\
know they & & & & \\
have a & & & & \\
mental & & & & \\
illness & & & & \\
\hline 5. Mental & & & & \\
illness is & & & & \\
different & & & & \\
from a & & & & \\
physical & & & & \\
illness & & & & \\
\hline 6. Treatment & & & & \\
is not needed & & & & \\
for mental & & & & \\
illness & & & & \\
\hline 7. There is & & & & \\
always & & & & \\
someone to & & & & \\
blame for & & & & \\
someone's & & & & \\
mental & & & \\
illness & & & & \\
\hline
\end{tabular}

APPENDIX H

Personal Beliefs Survey 
People have different experiences and feelings about people with mental illness. The next questions are about how you feel about people who have mental illness.

1. Would you be afraid to talk to someone who had mental illness?

Probably Unsure Probably Not

2. Would you be upset or disturbed to be in the same class with someone with mental illness?

Probably Unsure Probably Not

3. Would you make friends with someone who had mental illness?

Probably Unsure Probably Not

4. Would you feel embarrassed or ashamed if your friends knew that someone in your family had mental illness?

Probably Unsure Probably Not

People have different definitions of what "mental illness" means. Please write down your personal definition of what mental illness means.

APPENDIX I

Presentation Evaluation 
1. Has your knowledge about mental illness improved as a result of this presentation?

Not at all

Somewhat

Considerably

2. Has this presentation changed your attitude toward people with mental illness?

My attitude has become more positive

$\bigcirc$ My attitude hasn't changed

$\bigcirc$ My attitude has become more negative

3. What part of this presentation had the most benefit for you?

4. What part of this presentation would you improve?

5. Do you think that you will now act differently toward people with a mental illness as result of this presentation?
$\bigcirc$ Yes
Probably not
I don't know

\section{APPENDIX J}

\section{Demographic Questionnaire}


Age:

Gender:

Male

$\bigcirc$ Female

Grade:
$\bigcirc 9^{\text {th }}$
O $10^{\text {th }}$
O $11^{\text {th }}$
$\bigcirc 12^{\text {th }}$

Have you or someone you know ever had to deal with mental illness?
$\bigcirc$ Yes
$\bigcirc \mathrm{No}$

Race/Ethnic Identity: Please check all that apply.

$\bigcirc$ American Indian/Other Native American

Asian/Pacific Islander

Black/African American

$\bigcirc$ Hispanic, Latino, or Spanish

White

Biracial/Multiracial (please specify)

Other: (please specify) 